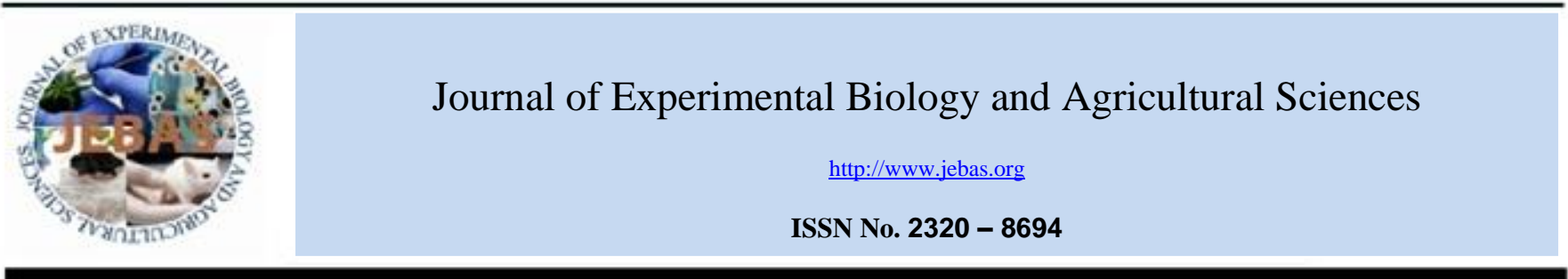

\title{
THE IGNORED PANDEMIC OF PUBLIC HEALTH CORRUPTION: A CALL FOR ACTION AMID AND BEYOND SARS-COV-2/COVID-19
}

\section{Jorge A. Sánchez-Duque ${ }^{1}$ (D), Zhaohui Su² (D), Diego Rosselli ${ }^{3}$ (D), Maria Camila Chica-Ocampo ${ }^{4}$ (D), Maria Isabel Lotero-Puentes ${ }^{5}$ (D), Ana M. Bolaños-Portilla ${ }^{1}$ (D), Manish Dhawan ${ }^{6,7}$ (D), Alfonso J. Rodríguez-Morales $^{8, *}$ (D), Kuldeep Dhama ${ }^{9, *}$}

\footnotetext{
${ }^{1}$ Grupo de investi

${ }^{2}$ School of Nursing, Center on Smart and Connected Health Technologies, Mays Cancer Center, University of Texas Health Science Center at San Antonio, San Antonio, Texas, 78229, United States of America

${ }^{3}$ Clinical Epidemiology and Biostatistics Department, Pontificia Universidad Javeriana, Medical School, Bogota DC, Colombia

${ }^{4}$ Faculty of Communication and Social Sciences, Universidad Autónoma de Occidente, Cali, Valle del Cauca, Colombia

${ }^{5}$ Faculty of Law, Political and Social Sciences, Universidad Libre, Campus Pereira, Pereira, Risaralda, Colombia

${ }^{6}$ Department of Microbiology, Punjab Agricultural University, Ludhiana-141004, India

${ }^{7}$ The Trafford Group of Colleges, Manchester-WA14 5PQ, United Kingdom

${ }^{8}$ Grupo de Investigación Biomedicina, Faculty of Medicine, Fundación Universitaria Autónoma de las Américas, Pereira, Risaralda, Colombia

${ }^{9}$ Division of Pathology, ICAR-Indian Veterinary Research Institute, Izatnagar, Bareilly 243 122, Uttar Pradesh, India
}

Received - March 18, 2021; Revision - April 03, 2021; Accepted - April 13, 2021

Available Online - April 25, 2021

DOI: http://dx.doi.org/10.18006/2021.9(2).108.116

\section{KEYWORDS \\ COVID-19 \\ Coronavirus \\ Pandemics \\ Corruption \\ Global Health}

\begin{abstract}
Corruption in healthcare is on the rise. When corruption infiltrates global health, causes embezzlement of public health funds, malfunctioning medical equipment, fraudulent or ineffective health services such as expired medicines and fake vaccines that could have life-or-death consequences. A corrupt healthcare system, amid global health crises like the COVID-19 pandemic, when resources are in constraint and trust is in high demand, can lead to devastating, though avoidable, health and economic consequences. It is imperative for policymakers, health experts, patients, caregivers, and global health funders to promptly acknowledge and address corruption in healthcare. The current pandemic generates an emergency and disorder state on health care systems across the globe, especially in low- and middleincome countries, where a weakening of control measures is evident, creating the perfect storm for corruption. This paper builds on existing research to examine processes that support essential stakeholder
\end{abstract}

* Corresponding author

E-mail: alfonso.rodriguez@uam.edu.co_(Alfonso J. Rodríguez-Morales); kdhama@rediffmail.com (Kuldeep Dhama)

Peer review under responsibility of Journal of Experimental Biology and Agricultural Sciences.

Production and Hosting by Horizon Publisher India [HPI] (http://www.horizonpublisherindia.in/).

All rights reserved.
All the articles published by Journal of Experimental Biology and Agricultural Sciences are licensed under a Creative Commons Attribution-NonCommercial 4.0 International License Based on a work at www.jebas.org.

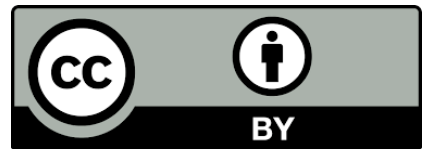




\section{Fraud}

Social Responsibility

Public Health Systems

Research

Economics

engagement in anti-corruption efforts. In this context, an extensive review of literature has been conducted by using various databases such as PubMed, Science direct, SCOPUS, Research Gate, and Google Scholar and a total of 45 articles and documents on corruption and COVID-19 were screened and selected by authors independently. To fill the knowledge gaps about the need for actions to be taken during a pandemic like COVID-19, we propose an anti-corruption grassroots movement that focuses on changing the social norms surrounding corruption in healthcare. By pushing forward a practice that normalizes conversations about corruption in everyday health practices and involving more stakeholders in the protection of public health resources, we argue that not only local health systems can become more resilient and resistant to corruption, but also global health initiatives can become more effective and efficient to improve individual and global health.

\section{Introduction}

Healthcare systems of several developing countries are already under crisis due to the lack of funding in government settings, privatizations of hospitals, and overburdening because of population explosions. Besides, that slap of corruption in healthcare systems worsening the availability of essential health care facilities to the public, especially during the pandemics like COVID-19. Moreover, corruption can be defined as "private individuals or enterprises who misuse public resources for private power or political gains" (Lindgreen, 2004). While corruption is an old phenomenon (Gaitonde et al., 2016; Hutchinson et al., 2019; Wierzynska et al., 2020), COVID-19 has spotlighted corrupt healthcare systems and has renewed concerns on society's lack of practical solutions against this other silent pandemic (Gallego et al., 2020; Ruiz-Estrada, 2020). During the COVID-19 outbreak, when hope is frail, and help is often far away, the incidence of corruption is on the rise (Burke, 2020; Nyoka, 2020; Chauvin, 2021).

Further, corruption and inefficient systems undermine healthcare systems' capacity to contribute to better health, industrial growth, and development (Vian, 2020). The corruption in the procurement of essential pharmaceuticals and medical devices, recruitment of health care providers, or distribution of vaccines and drugs has severe consequences on public health (Mackey et al., 2017; García, 2019; Sekalala et al., 2020). It is an urgent call to mitigate these consequences, especially during the health crisis such as the COVID-19 pandemic (Rodríguez-Morales et al., 2020c; Sánchez-Duque et al., 2020a). Moreover, this unnerving phenomenon underscores the need for solutions to alleviate these practices in low- and middle-income countries (Gyimah-Brempong et al., 2006). Interruptions and repression of corruption are fundamental elements to strengthen healthcare systems globally (Mackey et al., 2016; Sánchez-Duque et al., 2020d) and are much needed to control the death toll among the population of several developing nations (Chetwynd et al., 2004).
Hence, in this paper, we aim to discuss the challenges countries face regarding corruption in public health sectors amid COVID-19 and practical solutions that can address these issues in the future.

\section{Why does it matter in the wake of COVID-19?}

COVID-19 has exerted substantial pressure on health systems worldwide (Rodriguez-Morales et al., 2020b). Over the course of the pandemic more than 2.7 million people have died out of more than 122 millions of confirmed cases of COVID-19. The situation is even more worrisome in low- and middle-income countries that lack the robust healthcare systems required to handle global health crises like COVID-19 (Pecho-Silva et al., 2020; Gil-Villa et al., 2021). COVID-19 has achieved an unprecedented clinical, political and economic impacts in these countries, where governmental and non-governmental institutions have had to scramble to get risk preparation and control processes in shape, with some countries having their public policies on strengthening health systems, improving infrastructure, designing prevention programs and training the general population overnight (Rodríguez-Morales et al., 2020a; Sánchez-Duque, 2020e).

There is no doubt that the economy will be seriously affected, achieving global economic losses that could exceed 1.1 trillion dollars, including the direct and indirect costs associated with preparedness and prevention (practices that mitigate risk), the event itself (expenses for medical care, the prohibition of commercial trips) and after-effects of the event (long-term job losses, lost education, disability and early mortality in the laboractive population) (Sánchez-Duque et al., 2020b; Sánchez-Duque et al., 2020c).

According to the gross domestic product (GDP), the Organization for Economic Co-operation and Development (OECD) predictions of economic growth according to gross domestic product (GDP) show a significant decrease for 2020 due to SARS-CoV-2. A situation that aggravates this scenario is the enormous external debt of low- and middle-income countries, excluding China, which have accumulated nearly 6 trillion dollars. Likewise, another 
uncertainty in the medium and long term would be the probable increase in taxes for the states' economic recovery (Sánchez-Duque et al., 2020c). Many countries have shown a significant economic impact, including a significant change in their currencies' exchange rate, primarily associated with the lower global price of commodities like oil or coffee. Many companies are at risk of bankruptcy (Sánchez-Duque et al., 2020c).

Additionally, different from scandals, which can be seen in all types of societies worldwide, corruption is more likely to happen in low- and middle-income countries, often with limited economic prowess and pronounced social inequality (Gyimah-Brempong et al., 2006). The confluence of poverty, inequality, ill-guarded resources, imbalance of power, and lack of good governance often is the key for corruption to take hold in society (Chetwynd et al., 2004). Furthermore, in many nations, bribery has also been attributed to the implementation of social distancing policies. People living in far highly corrupted regions are much less willing to adhere with lockdown directives, as per a large study supported by evidence across almost 50 states in the Americas (Dincer \& Gillanders, 2021). This could be argued that bribery in different public services, such as healthcare services and police departments, would affect people's attitudes towards laws and their abilities to obey public health policies (Dugast et al., 2020; Saliba \& Taher, 2021).

\section{What are the challenges low- and middle-income countries face regarding corruption in public health sectors?}

In pre-pandemic time, public health was going through an extraordinary period, characterized by significant development that facilitated health promotion and disease control and an increasing amount of resources and improved access to healthcare (Mackey et al., 2017; García, 2019; Hernández-Vásquez et al., 2020). However, despite these characteristics, which in theory should achieve substantial results, they are still limited in terms of access to health services, effectiveness and sustainability of health systems due to planning, implementation, and presence of corruption (Gaitonde et al., 2016; Sánchez-Duque et al., 2020d).

Further, Corruption results from intentionally malicious behaviors that ignore general rules, regulations, and laws, a practice that replicates and spreads like a virus, threatening global public health progress (Mackey et al., 2016; García, 2019; Lu et al., 2020). It is a pandemic usually ignored with great diversity and scope, ranging from mild actions such as absenteeism and bribery to severe embezzlement cases and influence-peddling in essential positions of national governments (Burke, 2020; Nyoka, 2020; Vian, 2020). That makes it extremely difficult to design effective programs to prevent, detect, and control these health sectors' practices (Lu et al., 2020; Seakale et al., 2020). For this reason, despite constant investments by governments to increase professional staff, improve infrastructure and offer additional services, many people still struggle to access the health service they need, generating devastating consequences for the health of the population and multimillionaire economic losses sometimes difficult to identify (Mackey et al., 2017; Lu et al., 2020).

Corruption can have different distinctions; it can be considered "big" or "small"; it can be considered political or institutional; it can be generalized or individual; however, the common factor is that it is always carried out consciously and intentionally. Therefore, the participant recognizes that their behavior is not based on traditional policies or codes of conduct; therefore, they seek to avoid detection (Mackey et al., 2016; Dugast et al., 2020; Sekalala et al., 2020).

The motivation of different actors, including national governments, private companies, and criminal organizations, to contract with entities in the health sector is not surprising due to a large number of available resources, and the unique characteristics that give it a particular susceptibility to the deviation of these resources, given the public and private sector interaction (Mackey et al., 2017; Lu et al., 2020; Vian, 2020). A study published in 2013 by the nongovernmental organization transparency international reported that nearly $50 \%$ of the population in more than 42 countries consider that their health systems are corrupt or very corrupt, which constitutes the main barrier for the adequate development of solid health systems (Hutchinson et al., 2019; Mackey \& Cuomo, 2020; Sánchez-Duque et al, 2020d).

Despite being an open secret that violates individual and community human rights, little is being done to combat this problem, which, when incorporated into the health sector, exhibits even more dangerous behavior because it increases the risk of disability or even death, mainly affecting the most vulnerable people, such as the population of extremes ages and lower socioeconomic status (Radin, 2016; Koller et al., 2020).

The main factors that predispose to corruption are the concentration of power and money, which is why, within these systems, strong institutions are required, with shields that allow identifying and neutralizing any corrupt strategy, together with training and supervising each member so that they do not commit dishonest acts (García, 2019; Sekalala et al., 2020). Other factors that contribute to the perpetuation of corruption are the vagueness and ambiguity of concepts; corrupt practices sometimes seem to be the only means of accessing a health system service, such as bribes to obtain authorizations (Radin, 2016; Koller et al., 2020). This practice excludes those who cannot pay to receive these services. Power imbalances infringe investigative processes and judicial actions. When they are politically influential or wealthy, they usually fail to identify the principal agent, managing to deviate the guilt to lower-ranking officials (Gaitonde et al., 2016; Vian, 2020; 
Wierzynska et al., 2020). There is a lack of participation of multiple sectors interested in preventing corruption; absence of international zero corruption approach protocols with high validity and precision on how to tackle corruption, as well as the concept that it should not be studied since it constitutes a kind of attack to the health system (Mackey et al., 2016; Hutchinson et al., 2019).

Consequently, according to Teremetskyi, bribery and fraud in the form of theft in government procurement activities for the management of infections, misrepresentation of state contracts and financial fraud of public health care funds, corruption in administration, misuse of public funds, capitalism and preferential treatment of administration, fraud and theft of medical devices can all lead to severe consequences and aid into the death toll during disease outbreak (Teremetskyi et al., 2021).

Furthermore, the COVID-19 pandemic has spawned dozens of new challenging management problems in several countries. Such as unavailability of safe and reliable supply of standard medical supplies has posed as a concern for several countries all over the world (Sánchez-Duque et al., 2020d). The disease outbreak of COVID-19 has exacerbated current corruption stresses in acquisition of medical care in government settings, which range from disproportionate control to overt exploitation of public officials and public funds, necessitating effective governance responses. It has been postulated that the integrity and efficiency in procurement of medical devices and other facilities are critical in avoiding fraud issues that endanger health of the community (Kohler \& Wright, 2020; Mackey \& Cuomo, 2020; Chauvin, 2021).

Public health resources and facilities are the vital part of the health care systems and possess a pivotal role in improving health care of the community especially during an outbreak of infections. But the upcoming reports on the relatedness of corruption and disease outbreak put the public into a seriously dangerous situation (Kirya, 2020; Kohler \& Wright, 2020). Presently the available reports and literature have explored various different kinds of corruption and among these corruption and bribery in the recruitment and promotion of health-workers have serious impacts on health care in the community. The corruption in the recruitment practices also has a negative impact on the motivation and working capabilities of front-line health providers (Abbasi, 2020). Political and personal relationships instead of merit in the recruitment and promotion of health-workers in many countries can lead to severe consequences which in turn aid in the poor health care and increase in death rate in the community. Providing employment to the less qualified and unsuitable candidates over the deserving candidates and promoting poorly qualified workers have irreversible and deadly consequences for the community (Kirya, 2020). These practices especially in developing nations should be considered seriously (Radin, 2016; Koller et al., 2020).
Moreover, the corruption presents itself in different ways, including informal payments to providers, or illegal commissions on contracts, theft or diversion of medicines or supplies, embezzlement, among others (Gillon, 2013; Radin, 2016; Sekalala et al., 2020). Nevertheless, to achieve a holistic approach to corruption, it should be recognized that it does not occur only at the governmental or institutional plane, but also individually by some health professionals, who may exert influence for quick or better quality care, steal medicines or equipment from public institutions to use in private settings, accept functions or positions for which they are not trained or qualified, interfere in admission processes of undergraduate or specializations programs, receive benefits from pharmaceutical companies and promote the exclusive use of certain medicines, are absent from services, arrive late to their services, work in two places at the same time or use students to carry out the work for which they receive a salary through behaviors commonly called "mirror consultations" (Gillon, 2013; Randin, 2016; Hutchinson et al, 2019), among other corrupt strategies described by Sekalala (Sekalala et al., 2020).

Besides that, fraud and corruption in pharmaceutical sector posed a major threat to public health as it leads reduction in availability of drugs and vaccines to the community. Several obstacles such as medication scarcity and accessibility, overstocks, scarcity, theft, and surveillance of inadequate and faked drugs has been reported due to the corruption in acquisition of essential vaccines and drugs in government contracts. Digital technology and computerized systems of high quality should be introduced in the government sector to identify and deter widespread corruption in pharmaceutical companies (Mackey \& Cuomo, 2020).

Moreover, the primary goal of acquisition of drugs is to produce an adequate amount of high-quality medicines at reasonable rates for the community well-being. If fraud or any sort of corruption invades in the purchasing phase, this target will be jeopardized. Hence, the strategic procurement practices under strict regulations will help to reduce the potential misuse of resources while still ensuring that everybody has equal access to the necessary, highquality drugs especially when it is most needed in incidences like COVID-19 (Burki, 2019; Kohler \& Wright, 2020; Koller et al., 2020).

According to a recent extensive analysis of the literature it was concluded that the complex interplay in the health care system, and an inadequate governance has produced perfect circumstances for fraud in the Low - income countries of south Asia. In several Asian nations, mismanagement and a lack of effective government leading to corruption jeopardize the fair distribution of basic health care facilities, making it more expensive for the vulnerable and disadvantaged community to access the medical facilities and resulting in worse health care systems which in turn increasing the 
death toll in several regions especially the rural and undeveloped (Naher et al., 2020).

It was also discovered that inequalities in expenditure of funding and a lack of spending in health-care systems had seriously undermined every country's health-care systems (Saliba \& Taher, 2021) including the developed nations such as the USA, UK Russia and Germany. Poverty and inadequate wages, on the other hand in developing as well as developed nations, have also been attributed to disparities, which have intensified the dissemination of COVID-19 throughout the population or intensified the deleterious consequences in the disadvantaged community (Dhawan et al., 2020; Malik et al., 2020; Naher et al., 2020; Ojong, 2020).

\section{What practical solutions can address these issues?}

Corruption should be addressed as a global public health issue that impacts human development and requires urgent adjustments in legislation, public policies, clinical practices and established priorities. It is the root cause of low efficacy of health interventions, inequity in access, and trust loss in health institutions (Gaitonde et al., 2016; Hutchinson et al., 2019; Vian, 2020; Wierzynska et al., 2020).

Corruption is embedded in systems, organizations, and professionals associated with the health sector to the extent that these situations are considered "normal" in some countries. But national and international strategies to confront corruption have gained numerous corporations' attention, promoting scientific, moral and legal debates around the world (Mackey et al., 2016; Radin, 2016; Lu et al., 2020). WHO promotes the design of a global public health strategy among different international organizations with the collaborative objective of creating an internal control model with external participation, based on three principles: anti-corruption, transparency, and accountability (Koller et al., 2020). The proposed new model differs from the traditional approach in which corruption is theoretically prohibited and criminalized under punitive measures. It promotes alliances and preventive measures based on the risk model, looking at the components with the highest risk of corruption, looking for continuous surveillance and verification without altogether leaving aside the traditional punitive model (Koller et al., 2020; Wierzynska et al., 2020).

The previous anti-corruption approach is based on the fulfilment of processes that directly or indirectly support the provision of health services to meet programmed goals; in this model, as long as the established rules are followed and signed documents are available to support each process, no fraud or corruption will be acceptable. On the other hand, the new risk-based approach recognizes that despite complying with these standards, each of the processes carried out must be verified to determine if they contribute to each institution's general objective, improve health outcomes, and mitigate the risk of corruption (Wierzynska et al., 2020).

In this new model, anti-corruption mechanisms should focus on specific situations and consider: (i) process objectives; (ii) how the personnel who carry out the processes are chosen; (iii) transparency and documentation requirements; (iv) conditions of execution and payment of the process; (v) design of verification and supervision mechanisms; and (vi) incentives and sanctions for the actors involved in the process, among other components, discussed internationally (Gaitonde et al., 2016; Hutchinson et al., 2019; Vian, 2020; Wierzynska et al., 2020).

Government agencies, policy makers, and democratic institutions, on the other side, are struggling to combat corruption and improve openness and efficiency in order to achieve long-term sustainability in the health care system. In this context, Vian T, described conceptual frameworks and strategies that structure the interactions affecting the extent and severity of corruptions in the system and demonstrated that the various anti-corruption measures including openness, responsiveness, and public engagement will influence misconduct incidence, concluding how initiatives such as law enforcement will eliminate the prevalence of bribery and promote basic medical benefits (Vian, 2020).

Due to corruption in the health sector, there is a significant loss of resources, inadequate medical care, and worse health outcomes (Vian, 2020). Therefore, the first step is to talk about corruption in health, not only to know that it exists; therefore, creating academic and political dialogues that include all interested persons is required to mitigate this enormous public health problem (Hutchinson et al., 2019, Mackey et al., 2017). Anti-corruption mechanisms should be characterized by independence, impossibility to be manipulated or avoided, as well as generating little or no opportunity to abuse power (Wierzynska et al., 2020), for which the inclusion of social surveillance techniques play an essential role in monitoring the social and ethical performance of control systems (Sekalala et al., 2020).

"Justify the unjustifiable" is what some health systems do, characterized by being successful in avoiding being monitored (Hutchinson et al., 2019). Therefore, the design of anti-corruption interventions in global health still lacks in the fight against corruption. It is necessary to promote globally, through rigorous analyses that involve the participation of researchers from multiple disciplines with feedback processes and criticism of society in general, because it is necessary to promote critical thinking throughout society, to seek agreements between health professionals, administrators, politicians, journalists, and patients, until achieving the implementation of strategies that seek the benefit of the population, especially the most vulnerable ones 
(Mackey et al., 2016; Villanueva-Bedoya et al., 2017; García, 2019; Vian, 2020).

In future, technological advancements such as high-quality digitized system can be introduced to tackle corruption in the pharmaceutical industry to increase accountability, which reduces market manipulation in procurement of medicines and vaccines and thereby improves public health and enhance the availability of basic medicines to the community (Mackey \& Cuomo, 2020).

Electronic procurement of medicinal facilities through digital systems have been proven as a promising approach, but automated solutions for improving openness, government accountability, and combating corruption are yet to be explored (Mackey \& Cuomo, 2020). The method of pharmaceutical acquisition can be considered as a sensitive process especially in the healthcare services. Strict regulations, openness, inefficient processes can be strengthened in order to lower the likelihood of corruption (Kohler \& Wright, 2020).

Further, stringent procedures and regulations are urgently needed in the recruitment procedures to hire medical staff for providing health care in the community. Moreover, the recruitment criteria's of a range of officials such as government servants and healthcare providers must be open and clear according to legislations and regulations mentioned by international bodies including UNCAC (United Nations Convention Against Corruption) and the WHO Guidebook on monitoring and evaluation of Human Resources for Health. But, in future, it is required to start educating people about policies for the recruitment of medical staff on the merit basis (Kirya, 2020).

In addition to this, corruption free practices in research institutes will bring the laureates to the institutes. The clinical and research practices in the field of medicine, and medical education can be corruption free by introducing strict guidelines for the staff which in turn reduce the deleterious consequences of data fabrication in medical research. Furthermore, publishing and sharing the information on the problems and their possible solutions on authentic public databases will increase the transparency and openness at various levels of medical research, and education which will pave a path for better health care policies (Mackey \& Cuomo, 2020).

Moreover, governments and pharmaceutical industries should not announce critical policies in context with the science by press release. Misjudged actions might leave the science and pharmaceutical sector into the vulnerable position. A vivid and reliable study based on the concrete scientific data should be published for making policies regarding procurements of the drugs (Abbasi, 2020).
To conclude, currently, there is no solid evidence regarding successful strategies to reduce corruption; however, Latin America, a region significantly affected by COVID-19 (Malik et al., 2020), must heed the international call, because it is time to make significant changes in global public health, it is time to act against this ignored pandemic, making global approaches based on the best scientific evidence available and backed by international organizations that verify compliance and protection of health systems, guaranteeing the maximum physical and mental wellbeing of the world population (Sánchez-Duque et al., 2020d; Teremetskyi et al., 2021), with or without adaptations according to the social, cultural and political context of each community (Gillon, 2013; Gaitonde et al., 2016; Mackey et al., 2017; García, 2019; Wierzynska et al., 2020). COVID-19 still is a very complex condition with different points of view (Gil-Villa et al., 2021; Pecho-Silva et al., 2020; Malik et al., 2020). In future, it is essential to encourage more researchers and public officials to investigate this topic which will facilitate better global health solutions, particularly during pandemics like COVID-19. However, initiatives to boost efficiency in the health care systems sometimes neglect anti-corruption, openness, and regulatory framework. But corruption is a major burden on domestic health services and a considerable obstacle to reaching universal health care and sustainable development targets if it is not tackled (Burki, 2019). Hence, in the coming years to create better and sustainable health care systems, anti-corruption strategies should be implicated very strictly.

Author contributions: All the authors substantially contributed to the conception, compilation of data, checking and approving the final version of the manuscript, and agree to be accountable for its contents.

Acknowledgements: All the authors acknowledge and thank their respective Institutes and Universities.

\section{Funding: None.}

Conflict of interest: There exist no commercial or financial relationships that could, in any way, lead to a potential conflict of interest.

\section{References}

Abbasi K (2020) Covid-19: politicisation, "corruption," and suppression of science. BMJ (Clinical research ed.) 371: m4425. https://doi.org/10.1136/bmj.m4425.

Burke J (2020) South African police make arrests over notorious bank corruption scandal. The Guardian. https://www.theguardian.com/world/2020/jun/17/south-africanpolice-make-arrests-vbs-bank-scandal-notorious-corruption. Accessed on July 12, 2020. 
Burki T (2019) Corruption is an "ignored pandemic". The Lancet Infectious diseases 19(5): 471. https://doi.org/10.1016/S14733099(19)30178-1.

Chauvin L (2021) Peruvian COVID-19 vaccine scandal spreads. Lancet (London, England) 397(10276): https://doi.org/10.1016/S0140-6736(21)00508-0.

Chetwynd E, Chetwynd F, Spector BI (2004) Corruption and poverty: A review of recent literature. Manage System International 600:5-16.

Dhawan M, Angural S, Parmar M (2020) Tuberculosis during the covid-19: impact, challenges and management. Journal of Experimental Biology and Agricultural Sciences 8 (Spl-1- SARSCoV-2): S79 - S86. http://dx.doi.org/10.18006/2020.8(Spl-1SARS-CoV-2).S79.S86.

Dincer O, Gillanders R (2021) Shelter in place? Depends on the place: Corruption and social distancing in American states. Social $\begin{array}{llll}\text { Science } & \text { \& } & \text { Medicine } & \text { 269: }\end{array}$ https://doi.org/10.1016/j.socscimed.2020.113569.

Dugast A, Judais N, Nganyi F, Zhang H (2020) Tackling corruption in global health. Lancet (London, England) 396 (10245): 161-162. https://doi.org/10.1016/S0140-6736(20)30307-X.

Gaitonde R, Oxman AD, Okebukola PO, Rada G (2016) Interventions to reduce corruption in the health sector. The Cochrane Database of Systematic Reviews (8): CD008856. https://doi.org/10.1002/14651858.CD008856.pub2.

Gallego JA, Prem M, Vargas JF (2020) Corruption in the times of pandemia. Available at SSRN 3600572.

García PJ (2019) Corruption in global health: the open secret. Lancet (London, England) 394 (10214): 2119-2124. https://doi.org/10.1016/S0140-6736(19)32527-9.

Gillon JJ Jr (2013) In which wretched part of the world? A glimpse into western drug- and device-makers (and others) behaving badly. Indian Journal of Medical Ethics 10(3): 164-171. https://doi.org/10.20529/IJME.2013.051.

Gil-Villa DM, Sepúlveda-Arias JC, Martinez-Muñoz MA, Zuluaga-Vélez A, Hoyos-Pulgarin JA, Martínez JW, et al. (2021) Verificación del desempeño de la prueba rápida "AMP RAPID TEST SARS-COV-2 IGG/IGM- CASSETTES”. Infectio: revista de la Asociacion Colombiana de Infectologia 25(3): 169-175. http://dx.doi.org/10.22354/in.v25i3.942.

Gyimah-Brempong K, de Gyimah-Brempong SM (2006) Corruption, growth, and income distribution: Are there Regional
Differences?. Economics of Governance 7: 245-269. https://doi.org/10.1007/s10101-005-0008-2.

Hutchinson E, Balabanova D, McKee M (2019) We Need to Talk About Corruption in Health Systems. International journal of health policy and management 8(4): 191-194. https://doi.org/10.15171/ijhpm.2018.123.

Hernández-Vásquez A, Rojas-Roque C, Vargas-Fernández R, Rosselli D (2020) Measuring Out-of-pocket Payment, Catastrophic Health Expenditure and the Related Socioeconomic Inequality in Peru: A Comparison Between 2008 and 2017. Journal of Preventive Medicine and Public Health = YebangUihakhoe Chi, 53(4): 266-274. https://doi.org/10.3961/jpmph.20.035.

Kirya MT (2020) Promoting anti-corruption, transparency and accountability in the recruitment and promotion of health workers to safeguard health outcomes. Global Health Action 13 (suppl 1): 1701326. https://doi.org/10.1080/16549716.2019.1701326.

Kohler JC, Wright T (2020) The Urgent Need for Transparent and Accountable Procurement of Medicine and Medical Supplies in Times of COVID-19 Pandemic. Journal of Pharmaceutical Policy and Practice 13: 58. https://doi.org/10.1186/s40545-020-00256-w.

Koller T, Clarke D, Vian T (2020) Promoting anti-corruption, transparency and accountability to achieve universal health coverage. Global Health Action 13 (suppl 1): 1700660. https://doi.org/10.1080/16549716.2019.1700660.

Lindgreen A (2004) orruption and Unethical Behavior: Report on a Set of Danish Guidelines. Journal of Business Ethics 51: 31-39. https://doi.org/10.1023/B:BUSI.0000032388.68389.60.

Lu HS, Ho BX, Miranda JJ (2020) Corruption in Health Systems: The Conversation Has Started, Now Time to Continue it Comment on "We Need to Talk About Corruption in Health Systems". International Journal of Health Policy and Management 9 (3): 128132. https://doi.org/10.15171/ijhpm.2019.104.

Mackey TK, Cuomo RE (2020) An interdisciplinary review of digital technologies to facilitate anti-corruption, transparency and accountability in medicines procurement. Global health action 13 (suppl $1)$ : 1695241. https://doi.org/10.1080/16549716.2019.1695241.

Mackey TK, Kohler JC, Lewis M, Vian T (2017) Combating corruption in global health. Science Translational Medicine 9(402): eaaf9547. https://doi.org/10.1126/scitranslmed.aaf9547.

Mackey TK, Kohler JC, Savedoff WD, Vogl F, Lewis M, Sale J, Michaud J, Vian T (2016) The disease of corruption: views on how to fight corruption to advance 21 st century global health goals. 
BMC Medicine 14(1): 149. https://doi.org/10.1186/s12916-0160696-1.

Malik YS, Kumar N, Sircar S, Kaushik R, Bhat S, Dhama K, Gupta P, et al. (2020) Coronavirus Disease Pandemic (COVID19): Challenges and a Global Perspective. Pathogens (Basel, Switzerland) 9(7): 519. https://doi.org/10.3390/pathogens9070519.

Naher N, Hoque R, Hassan MS, Balabanova D, Adams AM, Ahmed SM (2020) The influence of corruption and governance in the delivery of frontline health care services in the public sector: a scoping review of current and future prospects in low and middleincome countries of south and south-east Asia. BMC Public Health 20 (1): 880. https://doi.org/10.1186/s12889-020-08975-0.

Nyoka S (2020) Coronavirus: Zimbabwe health minister in court on corruption charges. BBC. https://www.bbc.com/news/worldafrica-53119989. Accessed on July 12, 2020.

Ojong N (2020) The COVID-19 Pandemic and the Pathology of the Economic and Political Architecture in Cameroon. Healthcare $\begin{array}{lll}\text { (Basel, } & \text { Switzerland) } & \text { 8(2): }\end{array}$ https://doi.org/10.3390/healthcare8020176.

Pecho-Silva S, Navarro-Solsol AC, Arteaga-Livias K, PanduroCorrea V, Dhama K, Rodriguez-Morales AJ (2020) Possibilities of «Crushing» the Transmission Curve of COVID-19 in Latin America - We Still Have Time. Journal of Pure and Applied $\begin{array}{lllll}\text { Microbiology } & 14 & \text { (Suppl } & \text { 1): }\end{array}$ https://doi.org/10.22207/JPAM.14.SPL1.06.

Radin D (2016) Why health care corruption needs a new approach. Journal of Health Services Research \& Policy 21(3): 212-214. https://doi.org/10.1177/1355819615614870

Rodríguez-Morales AJ, Bonilla-Aldana DK, Tiwari R, Sah R, Rabaan AA, Dhama K (2020a) COVID-19, an Emerging Coronavirus Infection: Current Scenario and Recent Developments - An Overview. Journal of Pure and Applied Microbiology 14 (1): 5-12. https://doi.org/10.22207/JPAM.14.1.02.

Rodríguez-Morales AJ, Gallego V, Escalera-Antezana JP, Mendez CA, Zambrano LI, et al. (2020b) COVID-19 in Latin America: The implications of the first confirmed case in Brazil. Travel Medicine and Infectious Disease 35: 101613. https://doi.org/10.1016/j.tmaid.2020.101613

Rodríguez-Morales AJ, Sánchez-Duque JA, Hernández-Botero S, Pérez-Díaz CE, Villamil-Gómez WE, et al. (2020c) Preparación y control de la enfermedad por coronavirus 2019 (COVID-19) en América Latina. Acta médica Peruana 37(1): 3-7. https://doi.org/10.35663/amp.2020.371.909
Ruiz-Estrada MA (2020) Can COVID-19 generate a massive corruption in developing countries and least developed countries? Available at SSRN 3597367.

Saliba AN, Taher AT (2021) A land in agony: COVID-19, economic collapse, political corruption, and a deadly blast. American Journal of Hematology 96(1): E1-E2. https://doi.org/10.1002/ajh.26029.

Sánchez-Duque JA, Arce-Villalobos LR, Rodríguez-Morales AJ (2020a) Enfermedad por coronavirus 2019 (COVID-19) en América Latina: papel de la atención primaria en la preparación y respuesta. Atencion Primaria 52(6): 369-372. https://doi.org/10.1016/j.aprim.2020.04.001.

Sánchez-Duque JA, García-Guzmán DM, Barbery-Cardona V, Castillo-Castillo OE (2020b) Enfermedad por coronavirus 2019 (COVID-19): ¿Prevalecerá la economía o la vida en tiempos de pandemia?. Revista Mexicana de Medicina Familiar Available at https://doi.org/10.24875/RMF.20000072.

Sánchez-Duque JA, Orozco-Hernandez JP, Marin-Medina DS, Arteaga-Livias K, Pecho-Silva S, Rodríguez-Morales AJ, Dhama K (2020c) Economy or health, constant dilemma in times of pandemic: The case of coronavirus disease 2019 (COVID-19). Journal of Pure and Applied Microbiology 14 (suppl 1): 717-720. https://doi.org/10.22207/JPAM.14.SPL1.07.

Sánchez-Duque JA, Villanueva-Bedoya J, Alzate MF (2020d) La corrupción en salud pública: una pandemia ignorada. Salud publica de Mexico 62(5): 464-466. https://doi.org/10.21149/11229.

Sánchez-Duque JA (2020e) Educación médica en tiempo de pandemia: el caso de la enfermedad por coronavirus 2019 (COVID-19). Educación Médica $21 \quad$ (4): 259-260. https://doi.org/10.1016/j.edumed.2020.05.005.

Sekalala S, Masud H, Bosco RT (2020) Human rights mechanisms for anti-corruption, transparency and accountability: enabling the right to health. Global health action 13 (suppl 1): 1699343. https://doi.org/10.1080/16549716.2019.1699343

Teremetskyi V, Duliba Y, Kroitor V, Korchak N, Makarenko O (2021) Corruption and strengthening anti-corruption efforts in healthcare during the pandemic of Covid-19. The Medico-legal Journal 89(1): 25-28. https://doi.org/10.1177/0025817220971925.

Vian T (2020) Anti-corruption, transparency and accountability in health: concepts, frameworks, and approaches. Global Health $\begin{array}{llll}\text { Action } & 13 & \text { (suppl } & 1694744 .\end{array}$ https://doi.org/10.1080/16549716.2019.1694744. 
Villanueva-Bedoya J, Valencia-Guizado A, Alzate-Gonzalez MF, Wierzynska A, Steingrüber S, Oroxom R, Bauhoff S (2020) Sánchez-Duque JA (2017) Conocimiento científico y medios de Recalibrating the anti-corruption, transparency, and accountability comunicación: desafíos del periodismo científico en Colombia. formula to advance public health. Global Health Action 13 (suppl Revista Investigaciones Andina 19 (35): 105-116. 1): 1701327. https://doi.org/10.1080/16549716.2019.1701327. https://doi.org/10.33132/01248146.950. 